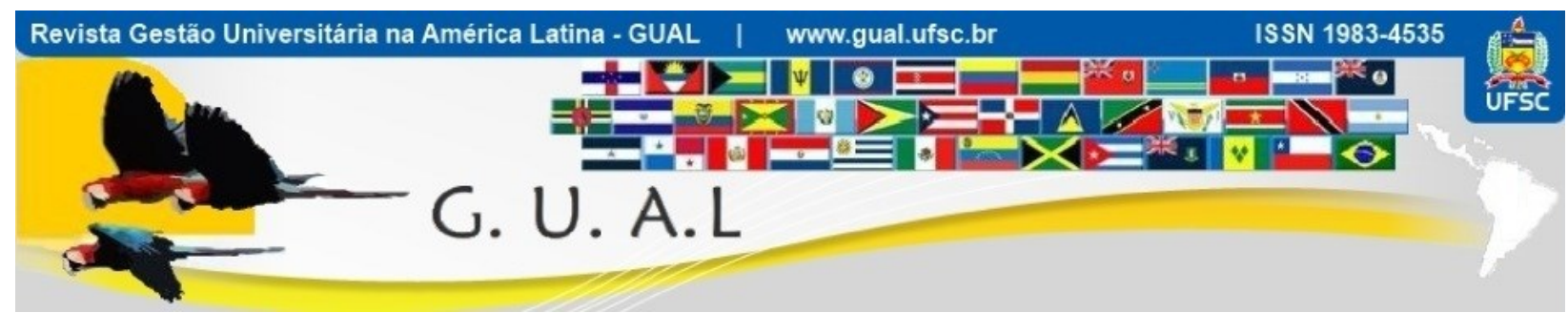

DOI: http://dx.doi.org/10.5007/1983-4535.2013v6n4p1

\title{
ANÁLISE DO PLANO DE DESENVOLVIMENTO INSTITUCIONAL DE INSTITUIÇÕES DE ENSINO SUPERIOR PARTICIPANTES DA ASSOCIAÇÃO DE UNIVERSIDADES GRUPO MONTEVIDEO - AUGM
}

\author{
ANALYSIS OF INSTITUTIONAL DEVELOPMENT PLAN FOR HIGHER \\ EDUCATION INSTITUTIONS PARTICIPATING IN THE GROUP ASSOCIATION OF \\ UNIVERSITIES MONTEVIDEO - AUGM
}

Junior de Mello, Bacharel Universidade Federal de Santa Maria - UFSM jr.melloadm@gmail.com

Lúcia Rejane da Rosa Gama Madruga, Doutora Universidade Federal de Santa Maria - UFSM luciagm@ufsm.br

Lucas Veiga Ávila, Mestre Universidade Federal de Santa Maria - UFSM admlucasveiga@gmail.com

Thiago Antônio Beuron, Doutorando Universidade Federal de Santa Maria - UFSM thyagobeuron@hotmail.com

Recebido em 29/novembro/2013

Aprovado em 29/novembro/2013

Sistema de Avaliação: Double Blind Review

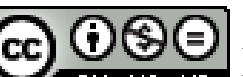

Esta obra está sob uma Licença Creative Commons Atribuição-Uso. 


\title{
RESUMO
}

O presente estudo tem como objetivo descrever o processo de planejamento, denominado de Plano de Desenvolvimento Institucional - PDI e o contexto de três universidades participantes da Associação de Universidades Grupo Montevideo - AUGM, localizadas em países da América Latina - Argentina, Brasil e Chile. Quanto ao método, o presente estudo classifica-se como multicaso e caracteriza-se como qualitativo, descritivo e exploratório, utilizando-se fonte de dados primários e secundários, coletadas na reunião do Núcleo Disciplinar de Avaliação Institucional, Planejamento Estratégico e Gestão Universitária da AUGM, realizada em agosto de 2012 na cidade de Assunção, Paraguai. Os resultados evidenciaram que as universidades consideram o processo de planejamento fundamental para orientar o seu processo de gestão e desenvolveram processos participativos utilizando-se de pesquisas, reuniões, seminários e consultas à comunidade universitária. As Instituições procuram desenvolver mecanismos para acompanhamento do PDI de modo a torná-lo ferramenta efetiva de gestão. O Núcleo de Planejamento da AUGM mantém discussões importantes sobre o tema. Destacou-se também que existe disparidades na forma de implementação e execução do planejamento entre as universidades participantes, ocorrendo problemas similares.

Palavras-chave: Planejamento. Plano de Desenvolvimento Institucional. Associação de Universidades Grupo Montevideo.

\begin{abstract}
The present study aims to describe the planning process, called the Institutional Development Plan - PDI and the context of the three participating universities of the Association of Universities Grupo Montevideo - AUGM located in Latin American countries - Argentina, Brazil and Chile. As for the method, this study is classified as multicase and is characterized as qualitative, exploratory and descriptive, using primary and secondary source of data, collected at the meeting of the Core Discipline of Institutional Assessment, Strategic Planning and Management University of AUGM held in August 2012 in Asunción, Paraguay. The results showed that universities consider the fundamental planning process to guide the process of management and participatory processes developed using research, meetings, seminars and consultations to the university community. Institutions seeking to develop mechanisms for monitoring the PDI in order to make it effective management tool. The Core Planning AUGM keeps important discussions on the topic. It was stressed that there is also variation in the implementation and execution of planning among the participating universities, similar problems occurring.
\end{abstract}

Keywords: Planning. Institutional Development Plan. Association of Universities Group Montevideo. 


\section{INTRODUÇÃO}

Reflexão, comportamento, complexidade, ação. Palavras cheias de significados que fazem parte da percepção de mudança em que a humanidade se encontra. Em sentido geral, os meios social, natural, econômico e político estão apontando cada dia mais para novas formas de interagir, na sociedade. O maior acesso à informação, a inserção de discussões sociais, as tendências e pactos mundiais sobre questões que assoberbam a todos, trazem a necessidade de modificação do modus operandi da sociedade atual. Mas qual o caminho a seguir?

A reflexão sobre a complexidade de temas e arranjos para um projeto de ação sustentável de países e regiões deve ser construída. Esse comportamento está profundamente enraizado na educação que age como elemento para a disseminação de novas práticas. As atitudes em prol do desenvolvimento de comportamentos mais adequados em relação ao uso e manutenção de recursos (água, solo, combustíveis fósseis), inúmeras vezes esbarram em infrutíferas tentativas. Cabe a indagação: "Por que isso acontece?" "Por que as práticas não evoluem se mudam constantemente os sujeitos"?

Um das formas para as organizações, em especial as Instituições de Ensino Superior - IES, buscarem novas formas para inserção desse novo sistema é o planejamento. Qual será o futuro dos próximos, 10, 15 anos? Vale ressaltar que as IES, como instituição formal existem há quase nove séculos, tendo evoluído desde a fundação de Bolonha, Paris e Oxford, pelas influências civis, religiosas, sociais, econômicas e também pelo desenvolvimento da ciência.

Nesse novo sistema, em especial para o Desenvolvimento Sustentável-DS, as universidades ocupam um papel central no desenvolvimento econômico, social, político do país (VILLARDÓN, 2012). Na América Latina devido ao contexto que os países estão inseridos, as universidades públicas ocupam um papel, valorizando o processo de planejamento. Stubrin (2012) salienta que o planejamento nas universidades irá romper paradigmas e trazer o pensamento de longo prazo na gestão universitária. Rinaldi (2002) afirma também que no contexto atual "não são mais toleráveis processos morosos, estruturas inchadas e infindáveis jogos de poder". O planejamento estratégico em universidade está deixando de ser um sinônimo, ou uma legislação pertinente, tornando-se um importante veículo/ferramenta de mudança na gestão, nas áreas pedagógicas, ensino e pesquisa.

As universidades públicas situadas na região do Cone Sul da América Latina, são entendidas como organizações que possuem dificuldades de planejar, e de trabalhar para o seu 
desenvolvimento (STUBRIN 2012). Muitas instituições interessadas em melhoria e progresso buscam por meio do Núcleo Disciplinar de Planejamento e Avaliação da Associação de Universidades Grupo Montevideo - AUGM organizar-se para inserir o planejamento estratégico em seu processo de gestão. Este grupo atua de modo cooperativo e proporciona aos participantes trocas de experiências sobre os processos de planejamento universitário.

No Brasil o planejamento estratégico das universidades é formalizado pelo Plano de Desenvolvimento Institucional - PDI, o qual se tornou uma exigência por meio da Lei N. 10.861, de 14 de abril de 2004, que estabelece o Sistema Nacional de Avaliação da Educação Superior - SINAES. O PDI consiste em um documento que tem a duração de cinco anos, no qual formaliza-se o perfil estratégico da Instituição, explicitando a missão, as estratégias, as metas e os objetivos, devendo contemplar o cronograma e a metodologia de implementação dos objetivos, metas e ações nas IES, observando a coerência e a articulação entre as diversas ações, a manutenção de padrões de qualidade e quando pertinente o orçamento (INEP, 2012).

Diante do exposto, o presente estudo tem como objetivo descrever o processo de planejamento, denominado de Plano de Desenvolvimento Institucional - PDI e o contexto de três universidades participantes da Associação de Universidades Grupo Montevideo - AUGM, localizadas em países da América Latina - Argentina, Brasil e Chile.

\section{PLANO DE DESENVOLVIMENTO INSTITUCIONAL - PDI}

No Brasil, O PDI foi inserido no contexto das Instituições de Ensino Superior - IES a partir da Lei N. 10.861, de 14 de abril de 2004, que estabelece o Sistema Nacional Avaliação do Ensino Superior - SINAES. O Ministério da Educação - MEC como parte integrante do processo avaliativo, caracterizou o PDI como o planejamento estratégico, conhecido também como plano estratégico das IES. De acordo com sua legislação vigente, o PDI deverá ser apresentado pela instituição na forma de novo processo no Sistema SAPIEnS ( Lei n 10.861 , de 14 de abril de 2004), no momento em que o interessado solicitar ao MEC, por intermédio do Sistema qualquer um dos seguintes procedimentos: (I) o credenciamento da Instituição de Educação Superior, (II) recredenciamento periódico de Instituição de Educação Superior (III) autorização de cursos superiores de graduação, tecnológicos, sequenciais, ou credenciamento de Instituição para a oferta de ensino a distância (IV) a autorização de cursos fora de sede para as universidades (INEP, 2012). 
Destaca-se que no Brasil, as IES deverão apresentar seus PDI's a cada cinco anos, tendo em vista o período de vigência estabelecido pela legislação. Os dispositivos legais de orientação à elaboração de PDI estão sintetizados no Quadro 1.

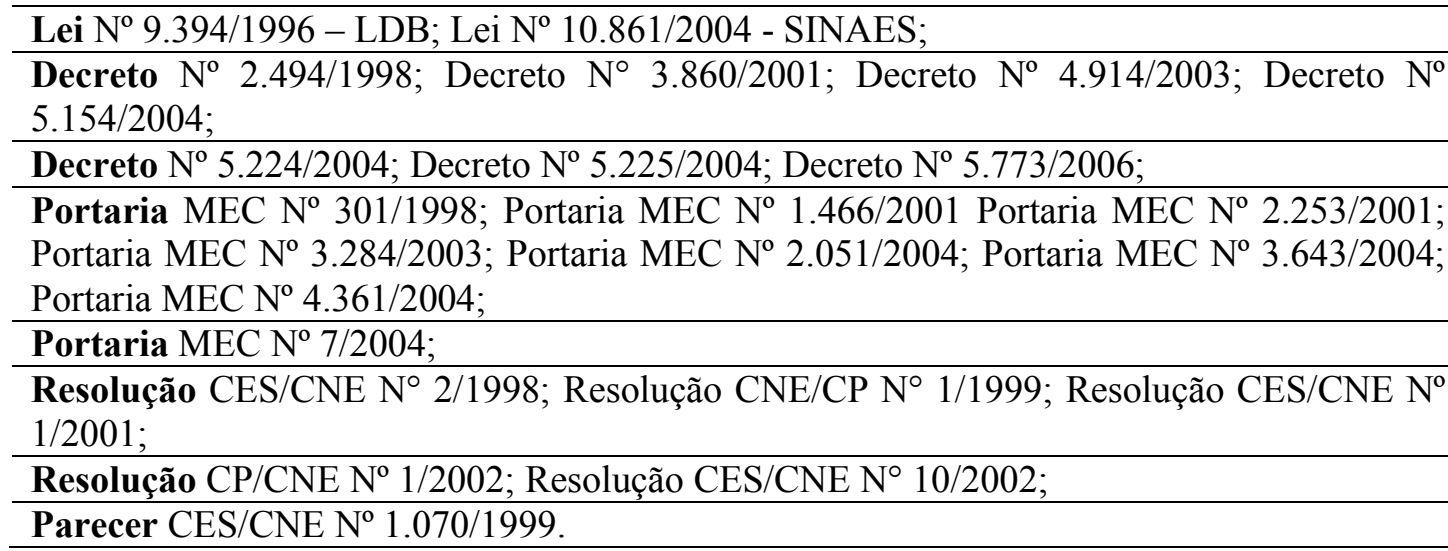

Quadro 1 Legislação pertinente, decretos e portarias

Fonte: Elaborado com base em (MEC, 2012).

O documento "Diretrizes para Elaboração do PDI", da Secretaria de Educação Superior - Sesu/MEC, de dezembro de 2004, apresenta a orientação geral, contendo os eixos temáticos essenciais que devem compor um PDI. O Decreto Presidencial N. 5.773, de 09 de maio de 2006, que dispõe sobre o exercício das funções de regulação, supervisão e avaliação de IES, apresenta no seu art. 16 os itens que deverão constar do PDI, como apresenta-se no Quadro 2.

A Portaria do MEC N. 40, de 12 de dezembro de 2007, que instituiu o Sistema E-MEC (Sistema eletrônico de acompanhamento de processos que regulam a educação superior no Brasil), dispõe sobre a utilização do PDI no processo de avaliação institucional externa e dos cursos de graduação da Instituição (MEC, 2012).

De acordo com as diretrizes do MEC o PDI consiste num documento em que se definem a missão da instituição de ensino superior e as estratégias para atingir suas metas e objetivos. Abrangendo um período de cinco anos, deverá contemplar o cronograma e a metodologia de implementação dos objetivos, metas e ações do Plano da IES, observando a coerência e a articulação entre as diversas ações, a manutenção de padrões de qualidade e quando pertinente o orçamento. Deverá apresentar ainda, um quadro-resumo contendo a relação dos principais indicadores de desempenho, que possibilite comparar, para cada um, a situação atual e futura (MEC, 2012). 


\begin{tabular}{|c|l|}
\hline I & $\begin{array}{l}\text { Missão, objetivos e metas da instituição, em sua área de atuação, bem como seu histórico de } \\
\text { implantação e desenvolvimento, se for o caso; }\end{array}$ \\
\hline II & Projeto pedagógico da instituição; \\
\hline III & $\begin{array}{l}\text { Cronograma de implantação e desenvolvimento da instituição e de cada um de seus cursos, } \\
\text { especificando-se a programação de abertura de cursos, aumento de vagas, ampliação das } \\
\text { instalações físicas e, quando for o caso, a previsão de abertura dos cursos fora de sede; }\end{array}$ \\
\hline IV & $\begin{array}{l}\text { Organização didático-pedagógica da instituição, com a indicação de número de turmas } \\
\text { previstas por curso, número de alunos por turma, locais e turnos de funcionamento e eventuais } \\
\text { inovações consideradas significativas, especialmente quanto à flexibilidade dos componentes } \\
\text { curriculares, oportunidades diferenciadas de integralização do curso, atividades práticas e } \\
\text { estágios, desenvolvimento de materiais pedagógicos e incorporação de avanços tecnológicos; }\end{array}$ \\
\hline V & $\begin{array}{l}\text { Perfil do corpo docente, indicando requisitos de titulação, experiência no magistério superior e } \\
\text { experiência profissional não acadêmica, bem como os critérios de seleção e contração, a } \\
\text { existência de plano de carreira, o regime de trabalho e os procedimentos para substituição } \\
\text { eventual dos professores da Figura; }\end{array}$ \\
\hline VI & $\begin{array}{l}\text { Organização administrativa da instituição, identificando as formas de participação dos } \\
\text { professores e alunos nos órgãos colegiados responsáveis pela condução dos assuntos } \\
\text { acadêmicos e os procedimentos de auto avaliação institucional e de atendimento aos alunos; }\end{array}$ \\
\hline VII & $\begin{array}{l}\text { Infraestrutura física e instalações acadêmicas com relação à biblioteca, laboratórios e plano de } \\
\text { promoção de acessibilidade; }\end{array}$ \\
\hline VIII & Oferta de educação à distância, sua abrangência e polos de apoio presencial; \\
\hline IX & Oferta de cursos e programas de mestrado e doutorado; \\
\hline X & Demonstrativo de capacidade e sustentabilidade financeiras. \\
\hline
\end{tabular}

Quadro 2 As dez diretrizes do PDI.

Fonte: Elaborado com base no MEC (2012).

Na Figura 01 estão apresentados os eixos norteadores do PDI.

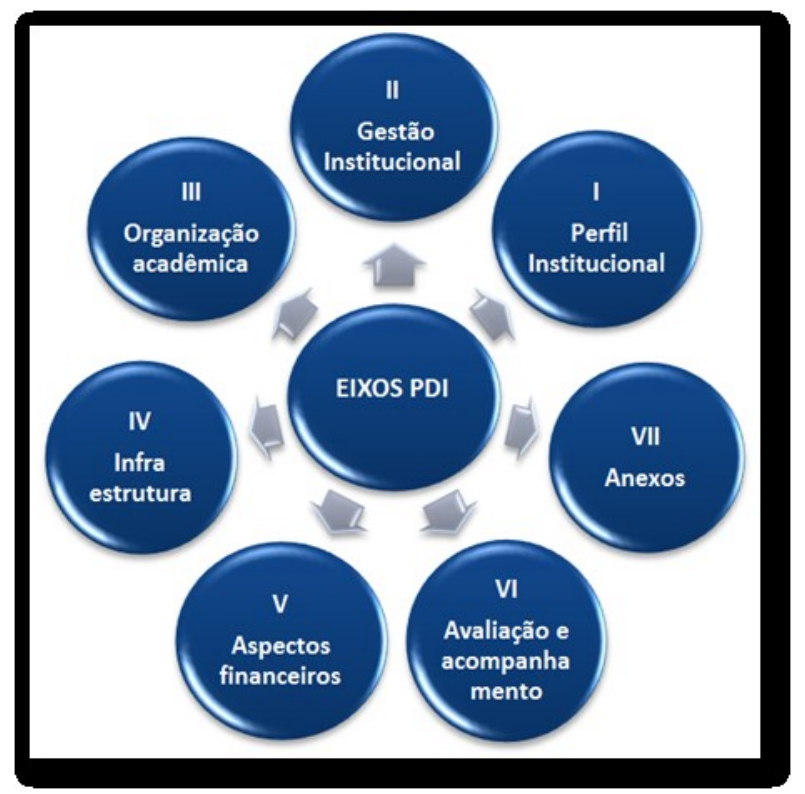

Figura 01 Eixos norteadores do PDI.

Fonte: Elaborado com base no MEC (2012).

O PDI deve estar intimamente articulado com a prática e com os resultados da avaliação institucional. Quando se tratar de Instituição já credenciada e/ou em funcionamento, os 


\section{ANÁLISE DO PLANO DE DESENVOLVIMENTO INSTITUCIONAL DE INSTITUIÇÕES DE ENSINO SUPERIOR PARTICIPANTES DA ASSOCIAÇÃO DE UNIVERSIDADES GRUPO MONTEVIDEO - AUGM DOI: http://dx.doi.org/10.5007/1983-4535.2013v6n4p1}

resultados das avaliações devem balizar as ações para sanar deficiências que tenham sido identificadas. No quadro 3, apresenta-se as descrições de cada eixo norteador do PDI.

\section{PERFIL INSTITUCIONAL}

\begin{tabular}{|c|l|}
\hline Perfil Institucional & $\begin{array}{l}\text { Breve Histórico da IES; Inserção Regional; Missão; Finalidades; Objetivos e Metas; Área (s) } \\
\text { de atuação acadêmica; Responsabilidade Social da IES; Políticas de Ensino; e Políticas de } \\
\text { Extensâo e Pesquisa. }\end{array}$ \\
\hline \multicolumn{1}{|c|}{ GESTÃO INSTITUCIONAL } \\
\hline $\begin{array}{c}\text { Organização } \\
\text { Administrativa }\end{array}$ & $\begin{array}{l}\text { Estrutura Organizacional, Instâncias de Decisão e Organograma Institucional e Acadêmico; } \\
\text { Órgãos Colegiados: atribuições, competências e composição; Órgãos de apoio às atividades } \\
\text { acadêmicas; Autonomia da IES em relação à Mantenedora; Relações e parcerias com a } \\
\text { comunidade, instituições e empresas. }\end{array}$ \\
\hline $\begin{array}{c}\text { Organização e } \\
\text { Gestão de Pessoal }\end{array}$ & $\begin{array}{l}\text { Corpo docente - composição, políticas de qualificação, plano de carreira e regime de } \\
\text { trabalho; Cronograma e plano de expansão do corpo docente, com titulação e regime de } \\
\text { trabalho, detalhando perfil existente e pretendido para o período de vigência do PDI; Corpo } \\
\text { técnico/administrativo - estruturação, políticas de qualificação, plano de carreira e/ou cargos } \\
\text { e salários e cronograma de expansão. }\end{array}$ \\
\hline Políticas de & $\begin{array}{l}\text { Formas de acesso, programas de apoio pedagógico e financeiro (bolsas); Estímulos à } \\
\text { permanência (programa de nivelamento, atendimento psicopedagógico); Organização } \\
\text { estudantil (Espaço para participação e convivência estudantil); Acompanhamento dos } \\
\text { egressos. }\end{array}$ \\
\hline Discentes
\end{tabular}

\section{ORGANIZAÇÃO ACADÊMICA}

\begin{tabular}{|c|c|}
\hline $\begin{array}{l}\text { Organização } \\
\text { Didático- } \\
\text { Pedagógica }\end{array}$ & $\begin{array}{l}\text { Plano para atendimento às diretrizes pedagógicas, estabelecendo os critérios gerais para } \\
\text { definiçãa de: Perfil do egresso; seleção de conteúdos; princípios metodológicos; processo de } \\
\text { avaliação; práticas pedagógicas inovadoras; políticas de estágio, prática profissional e } \\
\text { atividades complementares; políticas e práticas de Educação à Distância. }\end{array}$ \\
\hline $\begin{array}{l}\text { Oferta de Cursos e } \\
\text { Programas } \\
\text { (Presenciais e a } \\
\text { Distância) }\end{array}$ & $\begin{array}{l}\text { As Instituições, ressalvada a modalidade de ensino a distância, deverão apresentar dados } \\
\text { relativos ao número de vagas, dimensões das turmas, turno de funcionamento e regime de } \\
\text { matrícula de seus cursos. Informar ainda a situação atual dos cursos, incluindo o cronograma } \\
\text { de expansão na vigência do PDI conforme detalhamento a seguir: Graduação; Sequenciais; } \\
\text { Programas Especiais de Formação Pedagógica; Pós-Graduação (lato sensu); Pós-Graduação } \\
\text { (stricto sensu); Programas de Extensão; e Programas de Pesquisa. }\end{array}$ \\
\hline Infraestrutura & $\begin{array}{l}\text { Infraestrutura física; Infraestrutura acadêmica; Adequação da infraestrutura para o } \\
\text { atendimento aos portadores de necessidades especiais; Estratégias e meios para comunicação } \\
\text { interna e externa; e Cronograma de expansão da infraestrutura para o período de vigência do } \\
\text { PDI. }\end{array}$ \\
\hline $\begin{array}{l}\text { Aspectos } \\
\text { Financeiros e } \\
\text { Orçamentários }\end{array}$ & $\begin{array}{l}\text { Demonstração da sustentabilidade financeira, incluindo os programas de expansão previstos } \\
\text { no PDI: Estratégia de gestão econômico-financeira; Planos de investimentos; e Previsão } \\
\text { orçamentária e cronograma de execução ( } 05 \text { anos). }\end{array}$ \\
\hline $\begin{array}{l}\text { Avaliação e } \\
\text { Acompanhamento } \\
\text { do } \\
\text { Desenvolvimento } \\
\text { Institucional }\end{array}$ & $\begin{array}{l}\text { Projeto de Avaliação e Acompanhamento das atividades acadêmicas de Ensino, Pesquisa e } \\
\text { Extensão, Planejamento e Gestão; Formas de participação da comunidade acadêmica, técnica } \\
\text { e administrativa, incluindo a atuação da Comissão Própria de Avaliação - CPA, em } \\
\text { conformidade com o Sistema; Nacional de Avaliação da Educação Superior - SINAES; e } \\
\text { Formas de utilização dos resultados das avaliações. }\end{array}$ \\
\hline Anexos & $\begin{array}{l}\text { Projeto pedagógico do (s) curso (s) solicitado (s) para primeiro ano de vigência do PDI. } \\
\text { Nota: Os projetos dos cursos aqui elencados, para os quais está sendo solicitada autorização } \\
\text { de funcionamento, embora integrando o PDI, deverão constituir arquivos específicos } \\
\text { anexados em local apropriado, nas Pastas Eletrônicas da Instituição, no sistema } \\
\text { SAPIEnS/MEC. }\end{array}$ \\
\hline
\end{tabular}

Quadro 3 As dimensões do Plano de Desenvolvimento Institucional.

Fonte: Elaborado com base no MEC (2012). 
No entanto, verifica-se que as dimensões, servem como um guia, um roteiro de apoio às instituições, com o propósito de subsidiar a construção do PDI. Cabe salientar, que na elaboração do PDI deverá explicitar-se o modo pelo qual o documento foi construído e a interferência que exercerá sobre a dinâmica da Instituição, tendo como pressuposto o atendimento ao conjunto de normas vigentes. É imprescindível, na elaboração do PDI, considerar como princípios, a clareza e a objetividade do texto, bem como a coerência, de forma a expressar a adequação entre todos os seus elementos, e a factibilidade, de forma a demonstrar a viabilidade do seu cumprimento integral.

\section{MÉTODO}

O presente estudo caracteriza-se como qualitativo (DENZIN e LINCOLN, 2006). A pesquisa qualitativa apresenta as seguintes características essenciais: tem o ambiente natural como fonte direta de dados; o pesquisador como instrumento fundamental de coleta de dados; utilização de procedimentos descritivos da realidade estudada; busca do significado das situações para as pessoas e os efeitos sobre as suas vidas; preocupação com o processo e não simplesmente com os resultados e o produto, e privilégio ao enfoque indutivo na análise dos dados (BOGDAN; BIKLEN, 1994).

Segundo Gil (1999) a pesquisa caracteriza-se como exploratória e descritiva. Este tipo de pesquisa procura desenvolver, esclarecer e modificar conceitos e ideias com o intuito de formular problemas mais precisos para estudos posteriores e a pesquisa descritiva, descobre e observa fenômenos, na tentativa de descrevê-los, classificá-los e interpretá-los, sem, no entanto, ter o compromisso de explicá-los, embora sirva de base para a explicação (VIEIRA, 2005).

Quanto aos sujeitos da pesquisa, foram selecionadas três Universidades, a Universidade Federal de Santa Maria - UFSM, Brasil; Universidade Nacional do Litoral UNL, Argentina e Universidade de Playa Ancha - UPLA, Chile - classificando-se como um estudo multicaso Yin (2010) que se mostra adequado, pois tem sua conveniência atribuída aos fatores comuns nos casos selecionados.

Para a coleta de evidências nas 03 Instituições, foi elaborado um único protocolo, composto de categorias; para observação direta em entrevistas; observação nos documentos de planejamento e dos conselhos específicos de cada Instituição; observação em registro de arquivos repassados pelas Instituições e para observação participante. Para a condução das 
entrevistas em especial, foram considerados alguns aspectos (GIL, 1999), tais como: preparação do roteiro, estabelecimento do contato inicial, formulação das perguntas, estímulo a respostas completas, registro das respostas e conclusão da entrevista. Posteriormente foi realizado o levantamento de dados em duas fases (HAIR et al, 2005).

$\mathrm{Na}$ primeira fase, foram realizadas as entrevistas com representantes da área de planejamento das IES, e observações no encontro semestral das universidades que compõem o Núcleo Disciplinar de Avaliação Institucional, Planejamento Estratégico e Gestão Universitária da AUGM, ocorrido em maio de 2012, na cidade de Assunção, Paraguai.

$\mathrm{Na}$ segunda fase de coletas, em primeiro, foram selecionados os dados primários e secundários, obtidos no PDI, em documentos, legislação, site e publicações da universidade. Em segundo momento, realizou-se a coleta em documentos específicos de cada instituição: UFSM - UFSM (2012); MEC (2012); PDI (2011); UPLA - UPLAa (2012); UPLAb (2012); MINE (2012); CNA (2012); UNL - UNLa; (2012); CONEAUa (2012); CONEAUb (2012); ME (2012); UNLb (2010). Cabe destacar, que os princípios para a coleta de dados, que no uso de múltiplas fontes de evidências, tornou-se necessário á criação de uma base de dados, estudando posteriormente cada caso, para que logo após, fosse realizado um encadeamento das evidências.

Para a interpretação dos dados, adotou-se a análise de conteúdo, tendo em vista o contorno que a investigação assumiu, e esta pode ser definida como um conjunto de técnicas de análise, visando obter, procedimentos sistemáticos e objetivos das ações e estratégias para o planejamento das Universidades (BARDIN, 2009).

Os temas recorrentes foram agrupados segundo suas semelhanças e significados, dando-se, assim, ênfase as principais evidências para cada categoria. Deste modo buscou-se interpretar a problemática da pesquisa à luz da teoria revisada e a partir da valorização da fala dos entrevistados e documentos observados por meio da técnica de triangulação (PATTON, 2002).

$\mathrm{Na}$ seção dos resultados apresentar-se-á uma descrição sintética sobre o cenário de todas as universidades, sob o enfoque nas quais estão inseridas, seu processo de planejamento, características da gestão universitária, legislação, abrangência acadêmica, ensino, pesquisa, extensão, gestão e suas similaridades para o crescimento do país. 
4 O CONTEXTO ARGENTINO - UNIVERSIDADE NACIONAL DO LITORAL UNL

$\mathrm{Na}$ Argentina, verifica-se que o contexto atual do ensino começou a ser moldado com a Revolução Universitária de 1918, organizada pelos estudantes na cidade Córdoba. As universidades argentinas possuem grande similaridade nos currículos e todas as universidades públicas são autônomas, financiadas pelo Estado Argentino, que, além disso, organiza as diretrizes centrais do ensino, fiscalizando e certificando-as. Algumas universidades possuem também outras formas de angariar fundos, principalmente dos governos estaduais e do setor privado por meio da prestação de serviço. Assim, muitas universidades argentinas estão empenhadas com os seus processos de planejamento, haja vista, que estão preocupadas com o futuro do ensino depois da nova Lei de Ensino de 2007. O número de universidades particulares é crescente no país, principalmente pela grande evasão nas universidades públicas. As universidades oferecem bolsas de auxílio econômico, porém, ainda não é para a maioria que necessita. A Comissão Nacional de Avaliação e Certificação Universitária CONEAU, criada em 1996, é um órgão ligado ao Ministério de Educação que avalia as universidades e as certifica.

A Universidade Nacional do Litoral - UNL, constituída em 1919, está sediada na cidade de Santa Fé, Província de Santa Fé, Argentina. No princípio a Universidade abrangia toda a região do Rio Paraná, chamada de Litoral. A partir de 1956 a UNL foi desmembrada em várias Universidades, e a sua abrangência atual é a Província de Santa Fé. A Universidade conta com mais três campi, um na cidade de Esperanza, um em Reconquista e outro em Gálvez.

A UNL possuiu uma grande importância na construção da história argentina por ser a cidade de Santa Fé um importante palco das mudanças na constituição federal. Ela foi o primeiro fruto da reforma estudantil iniciada em 1918 e por muitos anos serviu de modelo à construção e reestruturação das universidades argentinas. Está sediada em uma região agrícola, com algumas indústrias de transformação e de bens duráveis e um importante polo da indústria cervejeira. Convertendo o orçamento em Dólares Estadunidense o orçamento da UNL é de US\$ 145.017.076,70. Cotizado ao valor oficial Argentino de \$4,51 em 15/06/2012.

A UNL possui um centro de idiomas, uma escola de nível primário, uma editora universitária, uma gráfica, sete institutos de investigação, três escolas de formação técnica, um clube recreativo, uma reserva ecológica, 12 bibliotecas, uma incubadora e um parque 
tecnológico. Conta com 44.000 alunos, 950 funcionários e 3.100 professores. São 9 unidades de ensino, 106 cursos de graduação e 64 de pós-graduação. Os alunos pós-graduação somavam 2.982 alunos em 2010, sendo a maioria da Faculdade de Ciências Jurídicas e Sociais e da Faculdade de Ciências Agrícolas. Em 2009, 1.820 alunos receberam o diploma em todos os níveis de ensino. Em 2009, aproximadamente 46\% dos formandos tinha mais de 29 anos de idade. No ano de 2009 a universidade mantinha 398 projetos de iniciação científica em funcionamento.

O processo de planejamento na UNL está a cargo da Secretaria de Planejamento, sob orientação do Reitor. A Instituição está no segundo PDI, sendo o primeiro relativo ao período de 2000-2010. Em meados de 2009 começou a ser trabalhado o planejamento para o período 2010-2019. O planejamento é visto como um ponto forte da UNL, e como um processo que já faz parte da Instituição. O PDI de 2010-2019 constitui-se no plano do centenário da Universidade e prevê o desenvolvimento de uma instituição sólida, com grande importância no cenário nacional e com ampla preocupação com a qualidade de ensino e com a formação cidadã. A UNL conta com uma assessoria externa do Centro de Estudos de Estado e Sociedade - CEDES que auxiliou na elaboração e na implantação do PDI. A Universidade também se baseou na avaliação externa da Comissão Nacional de Avaliação e Certificação Universitária - CONEAU e na sua autoavaliação interna.

O Planejamento da UNL é utilizado como um guia geral de estratégias, objetivos, metas e controles. O PDI da UNL definiu Linhas de Orientação Principais - LOP nas quais se enquadram os objetivos estratégicos que somam quatro para cada LOP e os objetivos específicos destes últimos. A Universidade trabalha para desenvolver uma gestão descentralizada por projetos, em que equipes multidisciplinares em conjunto trabalhariam para o desenvolvimento da Instituição. A Universidade realizará o acompanhamento e controle dos projetos por meio de um sistema informatizado

O primeiro passo do PDI 2010-2019 começou em 2009, e consistiu de pesquisas conduzidas pelo Observatório Social da UNL a fim de conhecer a opinião da comunidade universitária a respeito da imagem da UNL e suas expectativas para o decênio 2010-2019. O segundo passo foi um estudo Delphi em profundidade com 600 membros da comunidade universitária escolhidos ao acaso, que responderam perguntas sobre as tendências e as variáveis sobressalentes do primeiro estudo. O terceiro passo foi a reunião das informações dos dois primeiros passos no documento PDI que organizava as linhas gerais de orientação, os 
seus objetivos gerais e os seus objetivos específicos, aprovado em dezembro de 2010 . O quarto passo foi o guia de implementação do PDI para orientar a sua implementação, com a elaboração de critérios para prioridades e para a formulação e execução de projetos, assim como orientações para oportunidades de desenvolvimento dos projetos. O PDI 2010-2019 está estruturado em: (i) um sólido e desafiante ponto de partida; (ii) uma época de riscos e imperativos; (iii) a missão institucional: os compromissos irrenunciáveis; (iv) expectativas e previsões da nossa comunidade acadêmica; (v) convocatória a aprofundar a transformação e (vi) desenvolvimento explicativo das linhas de orientação principal.

Apesar de haver um consenso geral acerca da importância do planejamento, existem algumas dificuldades no campo político para garantir a integração entre as unidades acadêmicas em torno de projetos compartilhados e de grande expressão. O PDI do centenário, como é chamado, busca uma maior integração entre as faculdades, principalmente com a integração de carreiras e para que isso possa ocorrer é necessário um grande esforço político. Outra dificuldade enfrentada pela instituição é o apertado orçamento que há, assim, torna-se difícil criar novos projetos de desenvolvimento de grande porte.

\section{O CONTEXTO BRASILEIRO, A UNIVERSIDADE FEDERAL DE SANTA MARIA - UFSM}

No Brasil as Instituições de Ensino Superior - IES, em especial as Instituições Federais de Ensino Superior - IFES, têm a missão precípua de formar profissionais que atuarão no mercado ocupando posições de líderes de equipes, gestores, professores, políticos, dentre outras funções, os quais terão um papel de cidadãos que devem tomar para si a responsabilidade de gerar transformação social. Por meio desse contexto, as IES realizaram nas últimas décadas várias mudanças no intuito de promover uma inovação que possibilite incorporar á gestão não só os aspectos regulatórios, mas também gerar condições para que no processo de formação, sejam agregados aspectos da cidadania.

No pais as universidades públicas são financiadas por aporte de recursos do governo federal, por meio de financiamento ordinário e não ordinário. O Instituto Nacional de Estudos e Pesquisas Educacionais Anísio Teixeira - INEP é o órgão do MEC encarregado de realizar as avaliações no âmbito do ensino superior de graduação.

O contexto universitário brasileiro tem passado por grandes mudanças em anos recentes, após o Programa REUNI, lançado em abril de 2007, com o objetivo geral de ampliação do ensino superior e renovação pedagógica das universidades. O governo também 
incentivou a maior qualificação de professores e funcionários e aumentou a contratação de pessoal para as universidades. A pesquisa e a extensão receberam grandes aportes financeiros e foram criados muitos centros de investigação em todo o país. Por meio dos programas paralelos ao REUNI o governo estimulou, por exemplo, a mobilidade acadêmica de professores e alunos interna e externamente. No entanto, a adesão ao Programa foi voluntária. Segundo dados do Ministério da Educação - MEC durante os anos de 2008 e 2011 foram liberados cerca de dois bilhões de reais, e somente no primeiro ano do REUNI foram criadas mais de 15 mil novas vagas. Com o programa o governo criou 14 novas universidades públicas e também planeja criar 208 novos institutos técnicos até 2014 (MEC, 2012).

A Universidade Federal de Santa Maria - UFSM está sediada na cidade de Santa Maria, Estado do Rio Grande do Sul, Brasil e foi a primeira universidade pública fora do eixo das capitais estaduais. A Instituição abrange toda a região central, fronteira oeste e parte da região norte do Rio Grande do Sul e está dividida em quatro campi universitários: Santa Maria, Silveira Martins, Frederico Westphalen e Palmeira das Missões. A UFSM é a principal formadora de profissionais da região e está localizada em uma zona agrícola de pequenas e médias propriedades e com altos padrões de qualidade de vida. Dentro de sua área de abrangência predominam a indústria de transformação, de implementos agrícolas e de bens de consumo. Convertendo o orçamento em Dólares Estadunidense o orçamento da UFSM é de US\$ 424.002.279,20. Cotizado ao valor oficial Brasileiro de R\$ 2,04 em 15/06/2012 9 (Elaborado com base em: PDI).

A UFSM conta com uma incubadora tecnológica, hospital médico, hospital veterinário, clínica odontológica, farmácia universitária, três residências estudantis, editora universitária, gráfica universitária, creche universitária e centro de eventos onde se realizam feiras e importantes eventos. Conta com 26.924 alunos, 2.689 funcionários e 1.733 professores. São 10 unidades de ensino, 104 cursos de graduação e 91 de pós-graduação. Atualmente existem 410 grupos de pesquisas acadêmicas na Instituição, sendo a maioria dos grupos das Ciências Agrárias e Ciências da Saúde. A Instituição possui 4.476 alunos de PósGraduação, sendo a maioria das Ciências Agrárias, Ciências Naturais e Exatas e Ciências Sociais e Humanas. Em 2011 foram diplomados em todos os níveis e modalidades de ensino 4.929 alunos. Aproximadamente $68 \%$ do corpo docente possui nível de qualificação de doutorado. A UFSM aderiu ao REUNI recebendo um aporte total de recursos de R\$ 147.958.235,36 entre 2008 e 2011, incluindo custeio e investimento. 
O processo de planejamento, por meio do PDI, foi iniciado a partir da Lei N. 10.861, de 14 de abril de 2004. A UFSM possui um planejamento para o período 2011 a 2015 de acordo com as normas legais e utiliza-o como ferramenta administrativa. O planejamento da UFSM é gerenciado pela Pró-Reitoria de Planejamento (PROPLAN) com supervisão direta do Reitor. A Universidade está em seu terceiro PDI. O PDI 2011-2015 começou a ser trabalhado no início de 2010 e aprovado em julho de 2011. O PDI foi construído de acordo com os padrões legais vigentes. Durante todo o ano de 2010 a UFSM realizou uma troca de experiência com várias universidades brasileiras e estrangeiras. O plano estratégico da UFSM está divido em filosofia institucional, eixos norteadores, dimensões de atuação, objetivos estratégicos e planos de ação. É importante ressaltar que esses planos de ação estão divididos por áreas de atuação e cada unidade universitária possui seus próprios ações/projetos/programas. A instituição desenvolveu um sistema informatizado para o acompanhamento dos planos de ação.

O primeiro passo do processo de elaboração do PDI 2011-2015 foi a sensibilização da comunidade universitária. Para tanto, foram realizadas reuniões com as unidades universitárias e pró-reitorias, chamadas nos meios de comunicação universitária, envio de correspondências e mensagens no contracheque para todos os servidores, web email para toda a comunidade, cartazes, folders e outras formas e comunicação. O segundo passo foi o processo de elaboração do documento incluindo consultas à comunidade universitária por meio de um formulário na página web para contribuições quanto à filosofia institucional e eixos norteadores; reuniões com as unidades de ensino e de administração; I Seminário de PDI, que contou com palestras e ao fim a revisão da missão, visão, valores e eixos estratégicos em plenária; informações da auto avaliação realizada em 2010 assim como as propostas de planos de ação sugeridas pelas unidades acadêmicas e administrativas. $\mathrm{O}$ terceiro passo foi a compilação do documento PDI enviado para aprovação dos órgãos competentes. Após, a aprovação foi iniciado o processo de implementação. O documento de planejamento estratégico da UFSM com total de 262 páginas está estruturado com os seguintes eixos: (i) perfil institucional; (ii) constituição e organização administrativa e acadêmica; (iii) projeto pedagógico institucional; (iv) desenvolvimento acadêmico da instituição; (v) desenvolvimento administrativo e da gestão da instituição; (vi) autoavaliação institucional; (vii) atendimento às pessoas com necessidades educacionais especiais ou com mobilidade reduzida e(viii) demonstrativo de capacidade e sustentabilidade financeira. 
As maiores dificuldades encontradas pela Pró-Reitoria de Planejamento estão relacionadas com a mobilização política das unidades acadêmicas para participação no processo como um todo; falta de consciência sobre a importância do planejamento; falta de conhecimento gerencial por parte dos gestores; mobilização e participação da comunidade acadêmica; dentre outras questões.

\section{O CONTEXTO CHILENO, A UNIVERSIDADE DE PLAYA ANCHA - UPLA}

No Chile, em 1990 o governo lançou a Lei n. 18.962, Lei Orgânica Constitucional de Ensino que visava melhorar as condições financeiras das instituições tradicionais, a qualidade de ensino e a infraestrutura. O governou liberou linhas de créditos para que o endividamento familiar parasse de crescer. Esse fator tornou o sistema de ensino superior do Chile peculiar em comparação aos outros países estudados.

As universidades particulares cresceram consideravelmente nos últimos anos com uma proposta mais econômica, porém, muitas carecem de qualidade. As universidades públicas tornaram-se concorridas, nas quais geralmente estudam jovens com um bom poder aquisitivo e com uma boa formação secundária. O governo chileno ano a ano aumenta o número de bolsas nas universidades públicas para pessoas menos favorecidas economicamente. Porém, os estudantes chilenos estão insatisfeitos com essa situação e é constante o número de protestos por mudanças no sistema. Esses dados são do Ministério de Educação do Chile, e é visível a preocupação com a melhoria da educação superior. O Conselho Nacional de Certificação - CNA avalia e certifica as instituições de ensino superior. A realização do PDI não é obrigatória por Lei, mas muitas universidades públicas o realizam, principalmente porque necessitam de fundos para financiar-se e otimizarem o uso dos recursos.

A Universidade de Playa Ancha - UPLA está sediada na cidade de Valparaíso, Província de Valparaíso, Região de Valparaíso e sua figura jurídica foi constituída em 1985. Antes disso, a universidade fazia parte da Universidade do Chile como Faculdade de Educação e Letras. A Universidade abrange a região de Valparaíso e Vale do Aconcágua.

A UPLA, assim como as demais universidades públicas do Chile, é paga. Por isso, a Instituição possui uma grande preocupação com a qualidade do ensino e uma grande preocupação para com a sociedade e com o desenvolvimento do país. A Instituição possui um grande plano para auxiliar alunos que necessitam de ajuda social e financeira. Um dos objetivos que levou a criação da UPLA foi justamente a necessidade de melhor atender a 
região de Valparaíso e oferecer à região uma melhor opção de acesso ao ensino superior. A sede da Universidade está em uma região portuária de grande importância para Chile, onde há um polo pesqueiro, minas de cobre, indústria têxtil e alimentícia e fabricação de vinhos.

A UPLA conta com um instituto tecnológico, um centro de estudos avançados e um clube desportivo. Convertendo o orçamento em Dólares Estadunidense o orçamento da UPLA é de US\$ 56.106.576,63. Cotizado ao valor oficial Chileno de \$ 499,09 em 15/06/2012. Possui com 7.800 alunos, 510 funcionários e 618 professores. São 8 unidades de ensino, 35 cursos de graduação e 31de pós-graduação. Em seus programas de Pós-Graduação a Universidade possuía 572 alunos matriculados em 2010, distribuídos majoritariamente na Faculdade de Educação. Em 2010 a universidade diplomou 1.306 alunos ao total, ao mesmo tempo em que ingressaram 2.039 alunos novos em todos os níveis de ensino. Somente em 2010 a universidade começou a incentivar e a financiar projetos de pesquisa, além dos projetos de pós-graduação. Segundo a Direção Geral de Pesquisa, em 2010 foram 24 projetos, e a tendência é desenvolver ainda mais as linhas de pesquisa.

O Plano de Desenvolvimento Estratégico Institucional começou a ser organizado no ano de 2010 e foi concluído no primeiro semestre de 2011, para o período de 2011 a 2015 . O processo de planejamento é liderado pelo próprio Reitor da UPLA e conta com assessoramente técnico do órgão superior Direção Geral de Análises e Planejamento Estratégico Institucional - DAPEI. Ao lograr a aprovação pelas instâncias superiores o planejamento passou a ser executado pelas unidades acadêmicas e os diferentes órgãos da universidade. O Reitor da Universidade participou ativamente do processo e foi um dos principais responsáveis para que o PDI ocorresse. O planejamento estratégico da instituição também aborda de modo sintético as diretrizes pedagógicas para o período.

A Instituição atualizou sua missão, visão e filosofia, analisou o ambiente interno e externo, analisou tendências e definiu dois eixos estratégicos: Responsabilidade Social e Sustentabilidade Institucional. Estes eixos agrupam os objetivos estratégicos e atuam em conjunto com os âmbitos de atuação institucional. Assim, foi possível desenvolver planos de ação para cada eixo, âmbito e objetivo em concordância e relação com as variáveis ambientais analisadas. É importante ressaltar que até a elaboração do documento foram realizadas jornadas de trabalho envolvendo todos os representantes da Universidade. Essas jornadas eram realizadas durante todo um dia e ocorreram no final 2010 e início de 2011. 
O primeiro passo consistiu na revisão da missão, visão, princípios e valores. A universidade consultou a comunidade acadêmica por meio da página web e pelo contato direto com o DAPEI receberam sugestões e nas jornadas presencias de trabalho concluíram esta etapa. O segundo passo foi o diagnóstico estratégico. Foi utilizada a análise de forças, oportunidades; fraquezas e ameaças e uma a análise de contexto realizado por meio de uma pesquisa de mercado encomendada pela UPLA. O terceiro passo consistiu na definição dos objetivos estratégicos, por meio do Balanced Scorecard - BSC. O quarto passo projetou as metas e definiu os planos de ação. $\mathrm{O}$ quinto passo correspondeu à formulação do plano de acompanhamento, controle, avaliação e retroalimentação do PDI, a cargo do DAPEI. O sexto passo compreendeu o processo de comunicação. O PDI foi amplamente sociabilizado para toda a comunidade universitária e após isso, ocorreu a aprovação e institucionalização do documento pelas instâncias de aprovação, começando a sua implantação.

Apesar das suas 114 páginas o PDI é um documento de fácil compreensão por parte de não participantes do processo, sua estrutura compõem-se de: (i) apresentação; (ii) introdução: resenha histórica, estrutura organizacional e processo de planejamento; (iii) fundamentos estratégicos: missão, visão, filosofia corporativa; (iv) diagnóstico: análise FOFA, análise estrutural e conclusões; (v) formulação: eixos estratégicos, âmbitos institucionais, objetivos estratégicos, metas e indicadores, responsáveis, plano de ação e mapa estratégico; (vi) acompanhamento; (vii) anexos e (viii) glossário.

Segundo o DAPEI as maiores dificuldades encontradas para a implantação do PDI foram os constantes protestos dos estudantes no primeiro ano, de modo que a execução do planejamento ocorreu de forma restrita. A ambiciosa meta da UPLA é obter um grau de satisfação superior a 90\% dos alunos até 2015. Para isso, a Universidade buscou muitas formas de ter os alunos presentes e participativos na construção do PDI. Após a elaboração do Plano houve um grande trabalho para sua divulgação, e assim, sensibilizar a todos em torno do desenvolvimento da instituição.

O quadro 04 sintetiza as principais informações comparativas entre as três universidades analisadas. 


\begin{tabular}{|c|c|c|c|}
\hline Dimensões & UNL* & UFSM** & UPLA** \\
\hline País de origem & Argentina & Brasil & Chile \\
\hline Ano da fundação & 1918 & 1960 & 1985 \\
\hline Sede & Santa Fé & Santa Maria & Valparaíso \\
\hline $\begin{array}{c}\text { Orçamento em dólares } \\
\text { estadunidense }\end{array}$ & $145.017 .076,70 * * *$ & $424.002 .279,20 * * *$ & $56.106 .576,63^{* * *}$ \\
\hline Número de estudantes & 44.000 & 26.924 & 7.800 \\
\hline $\begin{array}{l}\text { Estudantes de pós- } \\
\text { graduação }\end{array}$ & 2.982 & 4.476 & 572 \\
\hline Número de professores & 3.100 & 1.733 & 618 \\
\hline Número de funcionários & 950 & $2.689 * * * *$ & 510 \\
\hline $\begin{array}{l}\text { Processo de } \\
\text { planejamento }\end{array}$ & $\begin{array}{l}\text { A cargo da } \\
\text { Secretaria de } \\
\text { Planejamento, sob } \\
\text { orientação do } \\
\text { Reitor }\end{array}$ & $\begin{array}{l}\text { Iniciado a partir da Lei N. } \\
10.861 \text {, de } 14 \text { de abril de } \\
2004 . \\
\text { Gerenciado pela } \\
\text { PROPLAN com supervisão } \\
\text { direta do Reitor }\end{array}$ & $\begin{array}{l}\text { Liderado pelo Reitor } \\
\text { com assessoramento } \\
\text { técnico da DAPEI }\end{array}$ \\
\hline Prazo do PDI & 10 anos & 5 anos & 5 anos \\
\hline Passos & $\begin{array}{l}\text { 1. pesquisas } \\
\text { conduzidas pelo } \\
\text { Observatório Social } \\
\text { da UNL } \\
\text { 2. estudo Delphi } \\
\text { em profundidade } \\
\text { 3. documento PDI } \\
\text { 4. guia de } \\
\text { implementação do } \\
\text { PDI }\end{array}$ & $\begin{array}{l}\text { 1. sensibilização da } \\
\text { comunidade universitária } \\
\text { 2. elaboração do } \\
\text { documento } \\
\text { 3. aprovação } \\
\text { 4. implementação }\end{array}$ & $\begin{array}{l}\text { 1. revisão da missão, } \\
\text { visão, princípios e } \\
\text { valores. } \\
\text { 2. diagnóstico } \\
\text { estratégico } \\
\text { 3. objetivos estratégicos } \\
\text { (BSC) } \\
\text { 4. projeção das metas e } \\
\text { planos de ação } \\
\text { 5. plano de } \\
\text { acompanhamento, } \\
\text { controle, avaliação e } \\
\text { retroalimentação } \\
\text { 6. Comunicação } \\
\end{array}$ \\
\hline $\begin{array}{c}\text { Acompanhamento do } \\
\text { PDI }\end{array}$ & $\begin{array}{l}\text { Sistema } \\
\text { informacional em } \\
\text { estudo }\end{array}$ & $\begin{array}{l}\text { Sistema informacional } \\
\text { desenvolvido }\end{array}$ & $\begin{array}{l}\text { Ainda não } \\
\text { informatizado }\end{array}$ \\
\hline Dificuldades & $\begin{array}{l}\text { No campo político } \\
\text { para garantir a } \\
\text { integração entre as } \\
\text { unidades } \\
\text { acadêmicas em } \\
\text { torno de projetos } \\
\text { compartilhados; } \\
\text { orçamento dificulta } \\
\text { o desenvolvimento } \\
\text { de projetos de } \\
\text { grande porte. }\end{array}$ & $\begin{array}{l}\text { Mobilização política das } \\
\text { unidades acadêmicas; falta } \\
\text { de consciência sobre a } \\
\text { importância do } \\
\text { planejamento e de } \\
\text { conhecimento gerencial por } \\
\text { parte dos gestores; } \\
\text { mobilização e participação } \\
\text { da comunidade acadêmica. }\end{array}$ & $\begin{array}{l}\text { Constantes protestos dos } \\
\text { estudantes no primeiro } \\
\text { ano, de modo que a } \\
\text { execução do } \\
\text { planejamento ocorreu de } \\
\text { forma restrita. }\end{array}$ \\
\hline
\end{tabular}

Quadro 4 Análise comparativa entre as universidades pesquisadas

*Dados de 2010 e **Dados de 2012

***Cotizado ao valor oficial Argentino de \$ 4,51, em 15/06/2012. Cotizado ao valor oficial Brasileiro de R\$

2,04, em 15/06/2012. Cotizado ao valor oficial Chileno de $\$ 499,09$, em 15/06/2012.

**** Incluindo os funcionários do Hospital Universitário. 


\section{CONSIDERAÇÕES FINAIS}

O presente estudo tem como objetivo descrever o processo de planejamento, denominado de Plano de Desenvolvimento Institucional - PDI e o contexto de três universidades participantes da Associação de Universidades Grupo Montevideo - AUGM, localizadas em países da América Latina - Argentina, Brasil e Chile.

As universidades públicas latino-americanas sofreram muitas mudanças a partir dos anos 90. Atualmente a democracia é o mantra mais poderoso dentro do campus universitário, e a qualidade de ensino com justiça de acessibilidade de ingresso, e a devolução de resultados para a sociedade se tornaram os três temas mais debatidos pelos gestores universitários. Dessa forma, o planejamento torna-se uma importante ferramenta de gestão na medida em que possibilita a priorização de projetos e a melhor alocação dos recursos. Apesar de considerarem o processo fundamental no atual contexto da gestão, as universidades analisadas apontam dificuldades no campo político, da participação, da implementação e do acompanhamento. As reformas no modelo de gestão do Estado e em todo seu aparato objetivam tornar o Estado mais eficiente e obter competitividade a nível internacional.

A Universidade Nacional do Litoral - UNL localizada na Argentina destaca-se pela atuação de quase um século de existência, sendo considerada de suma importância para a região de Santa Fé, além de servir de modelo para restruturação e construção de instituições daquele país. Destaca-se que a instituição encontra-se no segundo processo de planejamento, denominado PDI, o qual possui validade de 10 anos, enquanto no Brasil é de 05 anos. Outro fator a destacar que a instituição Argentina, possui apoio de uma assessoria externa do Centro de Estudos de Estado e Sociedade - CEDES, que auxilia na elaboração e na implantação do PDI. Uma vez que, na UFSM é realizada uma comissão interna, coordenada pelo Reitor e PROPLAN. Já na UPLA - Universidade Pública Chilena o PDI começou a ser organizado em 2010 e finalizado em 2011, possuindo a longevidade de 05 anos. O Plano de Desenvolvimento Estratégico Institucional Chileno, além do tempo de 05 anos possui uma caracterização semelhante à brasileira, pela liderança do Reitor e a estrutura do Plano.

As maiores diferenças do ambiente que vivem a universidade argentina e chilena para com a brasileira é o fato das duas primeiras realizarem o PDI por interesse, e a brasileira por força de lei. Fato este que não influencia no real interesse da UFSM em possuir um PDI estruturado e aplicável. A maior diferença do contexto argentino e brasileiro para com o 
chileno é o fato do ensino público das universidades públicas não é gratuito, existem mensalidades, fatos que não ocorre no Brasil e Argentina.

O estudo apresentou que existem disparidades nas três instituições pesquisadas, sendo um dos fatos marcantes a UNL na Argentina, à qual possui o maior contingente de alunos das três universidades pesquisadas, quase o dobro da UFSM, porém a UFSM possui um quadro de servidores quase três vezes maior que a UNL. Quanto ao sistema de acompanhamento do PDI, na UNL encontra-se em estudo, a UFSM encontra-se em funcionado e UPLA ainda não existe. Por meio de normatizações do MEC Brasileira, as universidades possuem em vigor regras e legislação que poderia servir de modelo para outras instituições para criação e acompanhamento do PDI, assim como softwares dos quais existe inúmeros, sendo um dos mais organizados o Sistema Integrado de Gestão do Mapa Estratégico do Ensino Superior SIGMEES, que encontra-se em implementação em algumas instituições Brasileiras.

Por fim, cabe expressar que este estudo trouxe contribuições para a compreensão do processo de planejamento universitário. Outrossim, verificou-se que os gestores estão motivados para busca de melhores condições no ensino, pesquisa e extensão, por meio do planejamento. Outra contribuição importante foi a possibilidade que se vislumbrou de observar as às diferenças entre culturas, orçamentos, números de alunos, foco e a missão das instituições, sendo estes fatores de suma importância para a compreensão da organização. Como limitação para o estudo, aponta-se a falta de documentos disponibilizados pelas Instituições, falta de critérios de divulgação de documentos para os pesquisadores.

Recomenda-se como agenda futura um estudo para verificar com as instituições pertencentes à AUGM, estão planejando suas ações e projetos vinculados ao PDI, com foco ao desenvolvimento sustentável. Propõe-se também um estudo para verificar qual o conhecimento que os servidores e docentes sobre o PDI e como ele avalia.

\section{REFERÊNCIAS}

BARDIN, L. Análise de conteúdo. LDA, Lisboa, Portugal. 2009.

BOGDAN, R. C.; BIKLEN, S. K. Investigação qualitativa em educação. Porto: Porto Editora, 1994.

COMISION NACIONAL DE EVALUACION Y ACREDITACION UNIVERSITARIA CONEAUb. Disponível em www.coneau.gov.ar/ Acesso em: 15 jun. 2012. 
COMISION NACIONAL DE EVALUACION Y ACREDITACION UNIVERSITARIA CONEAUa. Universidad Nacional Del Litoral: Informe de Evaluación Externa 29. 1 ed. Buenos Aires, Argentina, 2011

CONSEJO NACIONAL DE ACREDITACIÓN - CNA. Disponível em http://www.cnachile.cl/ Acessado em: 16 jun. 2012.

DENZIN, N. K.; LINCOLN, Y. O planejamento da pesquisa qualitativa: teorias e abordagens. 1 ed. Porto Alegre: Artmed, 2006.

GIL, A. C. Métodos e técnicas de pesquisa social. 5. ed. São Paulo. Ed. Atlas, 1999.

HAIR, J. et al. Análise Multivariada de Dados. $5^{\text {a }}$ ed. Porto Alegre: Bookman, 2005.

MINISTÉRIO DA EDUCAÇÃO - MEC. Sistema de acompanhamento de processos das instituições de ensino superior - SAPIEnS/ Plano de Desenvolvimento

Institucional/Diretrizes para elaboração. Disponível em

$<$ http://www2.mec.gov.br/sapiens/pdi.htm> Acesso em: Maio. 2012.

MINISTÉRIO DE EDUCACIÓN DE ARGENTINA - ME. Disponível em http://portal.educacion.gov.ar/ Acessado em: 18 jun.2012.

MINISTÉRIO DE EDUCACIÓN DE CHILE - MINE. Disponível em http://www.mineduc.cl/ Acessado em: 18 jun. 2012

Patton, M.Q. Qualitative research and evaluation methods. Thousand Oaks, CA: Sage Publications, 2002.

RINALDI, R. N. Adaptação Estratégica em Universidades Públicas: O caso da UNIOESTE. 21. ed. Cascavel: Coleção Thésis, 2002. 116 p. Disponível em http://www.unioeste.br/editora/pdf/rubia_rinaldi_adaptacao thesis protegido.pdf Acessado em: 18 jun. 2012.

SCHUCH, V. F. J. A Estruturação da Universidade em Questão: O caso da UFSM, Revista Brasileira de Administração, Brasília, v. 11, no 2, p. 1-113, jul./dez. 1995.

STUBRIN, A. Planes de Desarrollo Institucional en las Universidades Públicas: El caso de la Universidade Nacional del Litoral - Argentina. Universidad Nacional del Litoral. Santa Fe, 2012.

UNIVERSIDAD DE PLAYA ANCHA - UPLA. Disponível em < $\underline{\text { http://www.upla.cl/> }}$ Acessado em: 15 jun. 2012.

UNIVERSIDAD DE PLAYA ANCHA - UPLA. Plan Estratégico de Desarrollo Institucional 2010-2015. 1 ed. Valparaíso, Chile, 2010.

UNIVERSIDAD NACIONAL DEL LITORAL - UNLa. Disponível em http://www.unl.edu.ar/ Acessado em: 15 jun. 2012. 
UNIVERSIDAD NACIONAL DEL LITORAL - UNLb. Plan de Desarrollo Institucional 2010-2019: Hacia la Universidad del Centenario. 1 ed. Santa Fe de Vera Cruz, Santa Fe, 2010

UNIVERSIDADE FEDERAL DE SANTA MARIA - UFSM. Disponível em http://www.ufsm.br/ Acessado em: 15 jun. 2012.

UNIVERSIDADE FEDERAL DE SANTA MARIA. Plano de Desenvolvimento Institucional 2011-2015. 1 ed. Santa Maria, Brasil, 2011.

VIEIRA, M. M. F. Por uma boa pesquisa (qualitativa) em Administração. In: VIEIRA, M. M. F.; ZOUAIN, D. M. (Orgs). Pesquisa Qualitativa em Administração. Rio de Janeiro: FGV, 2005.

VILLARDÓN, L. Hacia una universidad competente. Revista Iberoamericana de Educación, v. 58, $\mathrm{n}^{\circ}$ 2, ago.2012. Disponível em http://www.rieoei.org/jano/4433Villardon.pdf Acessado em: 15 jun. 2012.

YIN, Robert K. Estudo de Caso: Planejamento e Métodos. Porto Alegre: Bookman, 2010. 